\title{
Is Laser the Best Energy Source to Perform Thermal Ablation?
}

\author{
Raffaella Tortora, Marco Guarracino, Maria Mattera and Giovan Giuseppe Di Costanzo* \\ Department of Transplantation, Italy
}

Received: 㠿: October 18, 2018; Published: 眥: October 31, 2018

*Corresponding author: Giovan Giuseppe Di Costanzo, Department of Transplantation, Italy

\section{Introduction}

Hyperthermic ablation is one of the most used treatment in patients with unresectable liver tumors. The primary mechanism of action of this treatment is the focally increase of temperatures $\left(>60^{\circ} \mathrm{C}\right)$ inside the tumor nodule in a relatively short period of time with the goal of inducing irreversible cell injury. Among hyper thermic ablative techniques, radiofrequency ablation (RFA) is the most popular. Since the first use of RFA in 1990, new devices and generator machines have been introduced in clinical practice. Two main problems of RFA are the limited efficacy in the treatment of nodules $>3 \mathrm{~cm}$ and the heat-sink effect when nodules are located near large vessels [1-10]. During the last years, to overcome these limitations, microwave ablation (MWA) has been increasingly proposed and employed also if two metanalyses have shown comparable efficacy of MWA and RFA. At the present, RFA and MWA have cornered the market due to the support by major vendors.

A third technique to perform the ablation of liver tumors with hyperthermia is laser ablation (LA). This treatment is less explored and few employed, and many reviews regarding hyperthermic ablation do not cite it. Not with standing, several retrospective studies and a randomized controlled non-inferiority study have shown that LA is as safe and effective as RFA to treat hepatocellular carcinoma within Milan criteria in cirrhotic patients [11-15]. The aim of this paper is to briefly describe the physics and biological effects of laser light during thermal ablation.

\section{Physics of Laser and Laser Tissue Interaction}

The description of LASER (Light Amplification by Stimulated Emission Radiation) principle was performed in 1917 by Albert Einstein, and after about thirty years laser energy was employed in the medical field. However only more than sixty years later, in 1983, Brown described for the first time the use of laser light to ablate a tumor. The delay between the discovery of the laser and its successful clinical application was likely due to the poor knowledge among physicians of laser physics and of the mechanisms that regulate laser-tissue interactions. A typical laser is composed of an optical cavity, a laser medium and two mirrors, one of them is semitransparent. The laser medium contains the atoms that stimulated by photons are reflected back and forth through this medium, thanks to the mirrors.

An external source of energy is needed to pump the electrons of laser medium in excited state. The light produced has three main characteristics. First, it is monochromatic being characterized by a single wavelength that defines the properties of the laser system and the extent of tissue penetration. Second, the laser beam is collimated and differently from conventional light sources it is very thin concentrating high energy amounts in limited areas. Third, it is temporally and spatially coherent because all the photons are in phase. Due to these characteristics, laser light is theoretically an optimal energy to treat locally liver tumors because it can be transmitted over long distances, delivered precisely and predictably into any location of the liver, limiting the effects on non-tumorous tissue. Solid state neodymium-doped yttrium aluminum garnet and diode lasers which have a wavelength of $800-1064 \mathrm{~nm}$ are the most used sources for performing LA of liver tumors. In particular, 1064 $\mathrm{nm}$ wavelength is preferred because belongs to the "therapeutic window" with a favorable tissue penetration/absorption ratio. We currently use a diode laser setted at $1064 \pm 10 \mathrm{~nm}$, having the advantage of being compact, silent and efficient.

We adopt the multifiber technique where laser light is delivered via flexible bare quartz fibers measuring $300 \mu \mathrm{m}$ in diameter with flat tip that are introduced inside the nodule through 21 gauge $(0.7 \mathrm{~mm})$ needles. These fibers have the characteristic of concentrating the high laser power on the very small tip that is in contact with the tissue. From this tip, laser light penetrates in the tissue forward for about $15 \mathrm{~mm}$ and the conversion of adsorbed light into heat determines the sharp increase in temperature. Above $60^{\circ} \mathrm{C}$, denaturation of proteins, coagulation and instant cell death occur. As temperature exceeds $100^{\circ} \mathrm{C}$ tissue water boils off and 
above $300^{\circ} \mathrm{C}$ charring happens, producing vapor. The carbonised black tissue hinders optical transmission, the heat accumulates locally and extends to the surrounding tissue by diffusion more than by direct optical transmission, therefore acting as a hot tip. Close to the tip of the illuminated fiber, tissue temperature is very high, above $250^{\circ} \mathrm{C}$. Therefore, in the central zone of the ablation area the tissue evaporates and carbonizes [16-22]. This area is surrounded by a zone of coagulative necrosis that is enclosed initially by tissue with hyperemia and haemorrhage, due to the increased blood flow stimulated by heat.

During the follow-up, these signs of congestion will be substituted by a dense rim of fibrotic tissue and all the nodule will become like a nutshell with an empty central zone due to the loss of tissue. After a first phase of direct hyperthermic injury that is related to the extent of applied energy, a second phase of indirect cellular damage follows causing the progression and the extension of tissue injury. Several mechanisms are involved in this delayed heat-induced damage as release of lysosomal contents and of cytokines, apoptosis, increase of tissue inflammatory cells and of immune response, and microvascular injury. This last effect is particularly relevant in the indirect damage that is induced by laser. Tumor vessels are more sensitive to heat stress than non tumoral vessels. LA is more efficient than other forms of heat generation in causing endothelial injury and thrombosis of micro vessels inducing a progressive tissue injury that may continue up to 3 days after the procedure.

LA in addition to local ablation of the tissue stimulates local and systemic Th1 type immune responses which may play a significant role in inhibiting tumor recurrence from residual micro metastases or circulating tumor cells and inhibiting tumor angiogenesis. A single thin bare fiber with flat tip that is illuminated for 6 minutes by a diode source with a wave length of $1064 \mathrm{~nm}$ and a power of $5 \mathrm{~W}$, releases 1800 joules and produces an elliptical area of ablation with diameters of $16-18 \mathrm{~mm}$ in length and $8-10 \mathrm{~mm}$ in width. To ablate larger areas, more fibers can be inserted and up to four of these can be simultaneously illuminated. Multiple fibers act synergistically increasing the volume of ablation of 4-11 times as it has been demonstrated also by a mathematical model . This synergistic effect has been described also for radiofrequency and for microwave.

However, using the radiofrequency the applicators are activated sequentially and not simultaneously as for laser and microwave, therefore the duration of the procedure is longer and the temperature increase inside the tumor is slower. Furthermore, an advantage of LA with the multifiber technique is the use of small devices and lower energy (5W), as compared to microwave and radiofrequency which employ 14-18 gauge devices and potency between $40 \mathrm{~W}$ and $150 \mathrm{~W}$. The use of thin fibres has the advantage of increasing the applicability of the procedure, in particular when nodules located in difficult areas should be treated.

\section{Conclusion}

Laser light is a very efficient energy source to perform thermal ablation. Experimental studies have shown that laser-tissue interaction may induce advantageous biological effects. Among these the main are the destruction of tumor microvasculature and the stimulation of immune response against cancer. Furthermore, laser light may be delivered with very thin applicators that increase the clinical applicability of the procedure.

\section{References}

1. Stauffer PR, Goldberg SN (2004) Introduction: Thermal ablation therapy. Int J Hyperthermia 20: 671-677.

2. Di Costanzo GG, Tortora R, D Adamo G, De Luca M, Lampasi F, Addario L, et al. (2015) Radiofrequency ablation versus laser ablation for the treatment of small hepatocellular carcinoma in cirrhosis: a randomized trial. J Gastroenterol Hepatol 30(3): 559-565.

3. Heisterkamp J, Van Hillegersberg R, Sinofsky E, IJzermans JN (1997) Heat-resistant cylindrical diffuser for interstitial laser coagulation: comparison with the bare-tip fiber in a porcine liver model. Lasers Surg Med 20(3): 304-309.

4. Chu KF and Dupuy DE (2014) Thermal ablation of tumours: biological mechanisms and advances in therapy. Nature Rev Cancer 14(3): 199208.

5. Hugander A, Bolmsjo M, Hafstrom L, Persson B (1983) Liver blood flow studies during local hyperthermia. An experimental study in rats. Clin Oncol 9(4): 303-310.

6. Walser E (2005) Percutaneous laser ablation in the treatment of hepatocellular carcinoma with a tumor size of $4 \mathrm{~cm}$ or smaller: analysis of factors affecting the achievement of tumor necrosis. J Vasc Interv Radiol 16(11): 1427-1429.

7. Nikfarjam M, Vijayaragavan M, Malcontenti Wilson C (2005) Progressive microvascular injury in liver and colorectal liver metastases following laser induced focal hyperthermia therapy. Lasers Surg Med 37(1): 64-73.

8. Matthewson K, Coleridge Smith P, O Sullivan JP, Northfield TC, Bown SG (1987) Biological effects of intrahepatic neodymium : yttriumaluminum-garnet laser photocoagulation in rats. Gastroenterology 93(3): 550-557.

9. Sorensen E, Gerber S, Frelinger J, Lord E (2010) IL-12 suppresses vascular endothelial growth factor receptor 3 expression on tumor vessels by two distinct IFN-gamma-dependent mechanisms. The journal of immunology 184(4): 1858-1866.

10. Lin WX, Fifis T, Malcontenti Wilson C, Nikfarjam M, Muralidharan V, et al. (2011) Induction of Th1Immune responses following laser ablation in a murine model of colorectal liver metastases. Journal of Translational Medicine 9: 83.

11. Vogl TJ, Wissniowski TT, Naguib NNN, Hammerstingl RM, Mack MG, et al. (2009) Activation of tumor-specific T lymphocytes after laser-induced thermotherapy in patients with colorectal liver metastases. Cancer Immunol Immunother 58(10): 1557-1563.

12. Tranberg KG (2004) Percutaneous ablation of liver tumours. Best Practice and Research: Clinical Gastroenterology 18(1): 125-145.

13. Heisterkamp J, Van Hillegersberg R, Sinofsky EL, IJzermans JNM (1999) Interstitial laser photocoagulation with four cylindrical diffusing fibre tips: importance of mutual fibre distance. Lasers Med Sci 14: 216-220.

14. Steger AC, Lees WR, Shorvon P, Walmsley K, Bown SG (1992) Multiplefibre low-power interstitial laser hyperthermia: studies in the normal liver. Br J Surg 79: 139-145.

15. Albrecht D, Germer CT, Isbert C, Ritz JP, Roggan A, et al. (1998) Interstitial laser coagulation: evaluation of the effect of normal liver blood perfusion and the application mode on lesion size. Lasers Surg Med 23(1): 40-47.

16. Ivarsson K, Olsrud J, Sturesson C, Möller PH, Persson BR et al. (1998) Feedback interstitial diode laser $(805 \mathrm{~nm})$ thermotherapy system: Ex vivo evaluation and mathematical modeling with one and four-fibers. Lasers Surg Med 22(2): 86-96. 
17. Bosman S (1993) Thermal effects of laser light on tissue structure Thesis. University of Amsterdam.

18. Goldberg SN, Gazelle GS, Dawson SL, Rittman WJ, Mueller PR, et al. (1995) Tissue ablation with radiofrequency using multiprobe arrays. Acad Radiol 2(8): 670-674.

19. Wright AS, Lee FT Jr, Mahvi DM (2003) Hepatic microwave ablation with multiple antennae results in synergistically larger zones of coagulation necrosis. Ann Surg Oncol 10(3): 275-283.

ISSN: 2574-1241

DOI: 10.26717/BJSTR.2018.10.001985

Giovan Giuseppe Di Costanzo. Biomed J Sci \& Tech Res

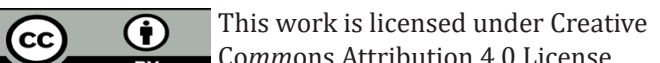

Submission Link: https://biomedres.us/submit-manuscript.php
20. Liang P, Wang Y, Yu XL, Dong B (2009) Malignant liver tumors: treatment with percutaneous microwave ablation-Complications among Cohort of 1136 patients. Radiology 251(3): 933-940.

21. Bruners P, Schmitz Rode T, Günther RW, Mahnken A (2008) Multipolar hepatic radiofrequency ablation using up to six applicators: preliminary results. Fortschr Rontgenstr 180(3): 216-222.

22. Lee JM, Han JK, Lee JY (2006) Hepatic radiofrequency ablation using multiple probes: ex vivo and in vivo comparative studies of monopolar versus multipolar modes. Korean J Radiol 7(2): 106-117.

$\begin{array}{ll}\text { BIOMEDICAL } & \text { Assets of Publishing with us } \\ \text { RESEARCHES } & \text { - Global archiving of articles } \\ \text { - Immediate, unrestricted online access }\end{array}$

